\title{
Communication Competency through Awareness of the 'Music' of English and the Influence of Culture on Language Acquisition
}

\author{
Chanchal Singh ${ }^{1}$, Sohani Gandhioke ${ }^{2}$ \\ Shantou University, English Language Center, Shantou University, Shantou-515063, \\ Guangdong, China
}

\begin{abstract}
:
This research examines the role of intonation as a significant contributor to the 'music' of spoken English. The authors will attempt to prove its importance and how it can be taught and learned in an EFL/ESL classroom. Additionally, the research reveals the influence of culture on language learning. The study, based on 110 university students, demonstrates the potential development of interest in speech proficiency, a positive attitude towards intercultural sensitivity, and its ultimate influence on social communication. Various devices make lexis and grammar more accessible to learners, but the methodology used for the transmission of intonation, and other prosodic features of articulation, make their acquisition very intangible and abstract. The result of the study stirred curiosity in the minds of the participants, who voiced a keenness to surmount their speech inadequacies and acquire the finer distinctions of spoken English, to become comprehensible speakers during a verbal exchange. The research and pedagogy resulted in observing the steady progress of the subjects and their feeling of empowerment due to the sense of achievement after speech perfection. The research demonstrated that teaching and learning intonation is possible if the learners are made aware of its significance during an oral discourse.
\end{abstract}

Keywords: Communication, comprehensibility, intonation, cultural influences, techniques for language acquisition 